\title{
Challenges and Opportunities for Community Participation in Monitoring and Evaluation of Government Projects in Tanzania: Case of TASAF II, Bagamoyo District
}

\author{
Bakari Iddi ${ }^{1}$, Said Nuhu ${ }^{2}$ \\ ${ }^{1}$ Department of Mathematics, Humanities and Social Sciences, National Institute of Transport, Dar es Salaam, Tanzania \\ ${ }^{2}$ Institute of Human Settlement Studies, Ardhi University, Dares Salaam, Tanzania \\ Email address: \\ bpandu2007@yahoo.co.uk (B. Iddi)sanutelaky@yahoo.com (S. Nuhu)
}

\section{To cite this article:}

Bakari Iddi, Said Nuhu. Challenges and Opportunities for Community Participation in Monitoring and Evaluation of Government Projects in Tanzania: Case of TASAF II, Bagamoyo District. Journal of Public Policy and Administration. Vol. 2, No. 1, 2018, pp. 1-10. doi: 10.11648/j.jppa.20180201.11

Received: December 10, 2017; Accepted: December 21, 2017; Published: January 10, 2018

\begin{abstract}
Community participation has become a critical concept, and it has greatly grown its importance in development policy and programmes. It is noted that it is important not only in assessing the needs, planning and implementation but also in the monitoring and evaluation (M\&E). This article examines the monitoring and evaluation of the government projects in Tanzania. It discusses the challenges and opportunities emanated from community participation drawing example from the 15 sub-projects selected in TASAF II national project in Bagamoyo District, Tanzania. In the collection of primary data, 55 beneficiaries and 17 key informants were selected purposively and were asked questions through questionnaires, in-depth interviews and focus group discussions. Direct field observation was also employed in order to get a real picture in the subprojects sites. The study revealed that despite TASAF policy of empowering communities to demand, implement and monitor services; community participation in M\&E still faced with many challenges such as; cost in terms of time and money, complexity of analysis and lack of analysis. It was also noted that despite having those challenges community participation in M\&E of TASAF II sub-projects the opportunities cannot be ignored. The study, therefore, recommends that the government, through TASAF, should have comprehensive monitoring and evaluation to ensure local communities are more active in making decision. In addition, more funds should be injected in empowering and building capacity to communities through training and technical support pertaining to monitoring and evaluation.
\end{abstract}

Keywords: Community Participation, Monitoring and Evaluation, Government Projects

\section{Introduction}

In recent years, participation has been realized as an important aspect to be included in development projects [1, 2]. Donors, governments and international organizations are advocating participatory approaches with integrating people's knowledge as the basis for planning and change $[3,4,5]$. In recognition of community participation in development perspective, there is also growing interest of making monitoring and evaluation more participatory. This makes the concept of Participatory Monitoring and Evaluation (PM\&E) to come in. The concept of PM\&E emerged in the 1970s, particularly from Non-governmental organizations (NGOs) work and in connection with new participatory approaches to development research. Since then, it has gained momentum in various donor and governments initiatives. Participation in $M \& E$ brings project stakeholders together to ensure appropriate effectiveness and efficiency of the project management [6]. It is a cultural process because it helps people to understand different issues, and it is a political process since it involves sharing of decisions making and empowering communities and with different actors regarding project implementation, management and sustainability [2].

Community participation provides local people with a great amount of experience and insights to planning, implementing and monitoring and evaluation of projects [7]. It is noted that participation can increase people's commitment to the project. In addition, participation of local people in M\&E can help them develop technical and managerial skills and thereby increase their opportunities for 
employment. Involving local people help to increase the resources available for programmes in a way to bring social learning for both beneficiaries and planners [7]. Again, in 2009, United Nations Development Program (UNDP) noted that community participation has been part of development policy, programmes and projects in both developing and developed countries. Participation improved quality, effectiveness and sustainability of development actions. By placing people at the centre of such actions, development efforts have a much greater potential to empower them and lead to ownership of the results [8].

Interest of involving community in $\mathrm{M} \& \mathrm{E}$ in the last decades was enhanced by international development communities [9]. They were not satisfied with conventional $\mathrm{M} \& \mathrm{E}$ in which communities are not actively participating. This approach is not encouraging voices of the poor to be heard adequately. Over the years, most of development interventions that aimed at reducing the poverty level have not participated local people in monitoring and evaluation. This has often resulted in non-sustainability of many development efforts. Practitioners and donors in development projects argue that communities should active participate in monitoring and evaluation in order to achieve pre-determined goals of projects or programmes [10]. However, community participation in $M \& E$ is a relatively new approach that many development agencies are still learning [11].

In Tanzania, currently, there is growing interest of involving primary stakeholders in all processes of development activities including monitoring and evaluation. The government incorporates aspects of monitoring and evaluation in national strategies, national planning, policies and programmes [12]. Since 2000, the government of Tanzania is implementing Tanzania Social Action Fund (TASAF), as part of the government strategies for reducing poverty and improving livelihoods by stimulating economic activities at the community level. TASAF has recognized community-driven approaches through which local people are involved in conception, execution and monitoring and evaluation in development projects. TASAF was established by the Government of Tanzania in 2000 as the tool of implementing the Government National Poverty Reduction Strategy. The TASAF project was established in phase; I and II. The TASAF II is an important national intervention project in Tanzania which aiming at reducing poverty at community level [13]. The project goal is to empower communities to access opportunities so that they could request, implement and monitor sub projects that contribute to improved livelihoods linked to national and global strategies; such vision 2025, Millennium Development Goals (MDGs) which changed to Sustainable Development Goals (SDGs) and National Strategy for Growth and Reduction of Poverty (NSGRP) [13]. There were some problems of community participation in M\&E of government projects in Tanzania especially in TASAF projects identified. Thus, necessitates the examining of the challenges and opportunities of community participation in TASAF II subprojects in Tanzania.

\section{Theoretical Underpinnings}

Community participation is a wider concept that varies with its context and the application and definition [3, 14]. For some, "it is a matter of principle; for others, practice; for still others, an end in itself" [14]. Community participation is the involvement of community in a project to solve their own problems [2]. Participation can involve processes such as information sharing, consultation, debate and empowerment. Local people can participate during needs assessment, planning, mobilization, training and implementation of the programs or project and monitoring and evaluation. Community participation is not to everyone in an identifiable community, since indigenous elites already have a strong voice in decision making, but rather to the poor majority with little access to resources and power [15]. The participation of community provides with previously disadvantaged group with the space actively participate in development activities affecting their lives [16]. Community participation should be perceived as participation in decision making, participation in the implementation of development programs and projects, participation in the monitoring and evaluation of development programs and projects and participation in sharing the benefits of development [17].

Community participation is not concerned with the mobilization of some individuals who should be regarded as the beneficiaries of participation rather; it involves the participation of the organized community [18]. The community participatory theory shows the two interrelated aspects that need to be taken into account when engaging in participatory development namely; empowerment and capacity building. Howard-Grabman et al., asserts that participation should impart local community with capacities and determine what has to be intervened and how [18]. Participatory institutions have to maximize opportunities to affect policy decisions. Neighborhood groups in the local context are basis for personal growth and self-transformation [19]. The strength of community participation is that, it cuts across traditional professional boundaries. Environment works better if the people affected by its changes are actively involved in its creation and management [20].

Effective community participation can lead to the project succession and lack of effective community participation can contribute to project failure to attain its goal. Effective community participation attains both interactive and spontaneous mobilization. Interactive participation is that beneficiaries join with external staff to analyze their situation, develop action plan, implement and monitor. In spontaneous mobilization, people take their own decision independently of external professionals to change their life situation. There are other important variables which can be achieved through community participation. These are community empowerment and building capacity to local people [10].

Participation is an empowering instrument to gain control over life enhancing systems and structures. Chamber asserts that participation is a fundamental right and a means of 
engaging poor people in joint analysis and development of priorities [21]. The ultimate goal should foster the existing capacities of poor, local women and men to increase their self reliance. The purpose of participation is to give a permanent voice to the poor or marginalized people and integrate them into mainstream decision making structures and processes that share their lives and the destiny of their society. Mwanzia and Strathdee, argue that involving of disadvantaged people has a great chance of ensuring effectiveness and efficiency in development of promoting transparency and sustainability of development than representing in policies and programs that affect them [22]. The TASAF report of 2008 pointed out that community participation is one of the key ingredients for empowerment of community and it is a critical success of the project. The participation of the intended beneficiaries and other stakeholders is emphasized to ensure ownership of sub projects, achievement of community empowerment as well as ensure relevance of sub projects to the needs of the beneficiaries [23].

However, Mansuri and Rao criticized community participation by arguing that the approach is too slow, time consuming and expensive. In addition, they asserted that the exercise of giving the voiceless, voice and choice could be costful under certain conditions [24]. In addition, participation may lead to psychological or physical pressure for the most socially and economically disadvantaged because genuine participation may require taking positions that are contrary to the interest of powerful groups. This is also in line with Nekwaya who asserts that community participation is more or less the same as realities in the sense that it is costful, time consuming and unpredictable human behavior can occur [25]. Therefore, one cannot predetermine the outcome of community participation. These criticisms should serve as an alarm to the development planners not to be satisfied with these approaches and realize that the potential benefits of participation do not suggest that, it is a solution for all development problems facing developing countries like Tanzania. It is this realization the participation may have its own set of costs and constraints that would help the development planners to plan properly and adhere to its underlying principles in order to produce the desired outcomes.

\section{Methods and Materials}

\subsection{Study Area}

The study was conducted in Bagamoyo District, Coast Region in Tanzania. It is located between $37^{\circ}$ and $39^{\circ}$ east, and between $6^{0}$ and $7^{0}$ south of the equator. It lies 75 kilometers (47 Miles) north of Dar es Salaam on the coast of the Indian Ocean, close to the Island of Zanzibar. Bagamoyo has 9,842 $\mathrm{km}^{2}$ total areas [26]. In Tanzania various government projects were established during 2000 as a tool for implementing government planning. Among others TASAF projects was established in phase I and II for purpose of reducing poverty at community level [13]. Regardless of the aim of the projects or empowering community still some challenges exist and thus hinder community participation in $\mathrm{M} \& \mathrm{E}$ of projects. TASAF II also received many claims of project failure in Bagamoyo district because the opinion and needs of the projects beneficiaries were ignored. Therefore, the District was chosen purposely since it was easy to obtain the necessary information needed by the researcher for the reason that the cases are information rich [27]. The District also, has many TASAF II projects beneficiaries and number of sub-projects as indicated in Table 1 compared to the other. This means that enable to get a real pictures of the benefit and challenges of community participation in $\mathrm{M} \& \mathrm{E}$.

Table 1. Selected sub-projects and their activities.

\begin{tabular}{ll}
\hline Selected sub-projects & Activities \\
\hline Construction of administration block Dunda sec. school & Block construction and management \\
Construction of Mkoko village dispensary & Organization of construction project \\
Fishing project (Ari mpya group)-Kaole & Fishing and sale of fish \\
Pineapple production group-Kiwangwa & Cultivation and sale of pineapple \\
Construction of Mjembe-Kwavuli road & Construction or road through small machine and manual labor \\
Construction of Tukamisasa-Mbuyo road & Construction or road through small machine and manual labor \\
Construction of Gongo-Mkange road & Construction or road through small machine and manual labor \\
Poultry-Matimbwa & Poultry \\
Poultry-Mataya & Poultry \\
Construction of classes- Kiromo sec. school & Block construction and management \\
Road upgrading Kibaoni- Kifuleta & Construction or road through small machine and manual labor \\
Magomeni fishing youth & Fishing and sale of fish \\
Fukayosi forest management & Protection of Fukayosi forest \\
Rehabilitation of Kwamduma-Kwavuli road & Contraction or road through small machine and manual labor \\
\hline
\end{tabular}

\subsection{Study Design}

This study employed a case study research design. The design enabled the researcher to examine monitoring and evaluation system of TASAF II sub-projects, how it works and its challenges. A case study is a systematic way of collecting information about a particular person, social setting, or a group and understands how it operates [28]. Furthermore, TASAF is the only government project dealing with projects related to poverty reduction at community level in Tanzania. Hence, easily to identify, the challenges and opportunities of in $M \& E$ at level of community. 


\subsection{Study Population and Sample Size}

The population of this study included key informants from TASAF headquarters officers, community beneficiaries, village council members, Village Executive Officers (VEO) and Village Fund Coordinator (VFC). The study employed purposive sampling technique to select project beneficiaries from different sub projects, local government officers and TASAF staff who had been working for a long time with TASAF projects so as to get a real picture of the challenges and opportunities in monitoring and evaluation of the selected sub-projects officer TASAF projects.

Table 2. Sample of the Respondents involve in the study.

\begin{tabular}{llll}
\hline Sample & Description & Total sample size & Experience \\
\hline Key informants & TASAF II HQ & 1 & 10 years \\
& Bagamoyo District & 1 & 12 years \\
& Village Executive Officer & 15 & 6 years \\
Project beneficiaries & From 15 sub-projects & 55 & \\
Total & & 72 & \\
\hline
\end{tabular}

\subsection{Data Collection Technique}

The study employed questionnaires, in-depth interviews, focus group discussion and direct field observations. Questionnaires was employed to collect data from 55 projects beneficiaries in order to understand their participation in monitoring and evaluation and the challenged they face and what are the opportunities they gain from the process. In depth interview was employed to $17 \mathrm{key}$ informants to collect information related to past experience in community participation in monitoring and evaluation. Focus group discussions (FGDs) were also employed to get an insight from three people who were 15 sub-projects beneficiary, 15 sub-projects leaders (part of the project beneficiaries) and 15 VEO. This means that, in each sub-project FGDs constitute three participations (1 sub-project leader, 1 sub-project beneficiaries and 1 Village Executive officer). This method was employed to get into deep discussion to allow interaction and discussion of the participation to get a real pictures of the challenges and opportunities of community participation in M\&E. Direct field observations was also employed to see the visited individuals sub-projects which is under TASAF II project. Through observation the researcher took notes on the activities in those visited projects. Documents review was also employed to reviewed sub projects reports, village meeting reports, TASAF II monitoring and evaluation framework, TASAF II Operational Manual, TASAF progressive report and other important documents.

\subsection{Data Analysis}

The study was qualitative in nature and the quantitative data was employed to back the qualitative information. Thematic analysis was used to analyze the qualitative data. Through thematic analysis, themes were identified and sorted based on specific themes and patterns relating to challenges and opportunities of community participation in M\&E. The quantitative data were analyzed by employing Statistical Package for Social Sciences (SPSS).

\section{Results}

\subsection{Level and Roles Community Participation}

Levels and roles of community participation in subprojects activities are important in understanding the challenges and opportunity of participatory M\&E. The findings indicated that community has been participated into different levels as summarized in Table 3.

Table 3. Roles played by Respondents in Sub project Activities.

\begin{tabular}{ll}
\hline Sub-projects cycle (levels) & Beneficiaries roles \\
\hline \multirow{3}{*}{ Needs assessment } & 1. Attending meeting for TASAF project awareness and sensitization raised by TASAF \\
& 2. Identify sub project priorities \\
3lanning & 3. Designing sub projects interest forms \\
& 1. Formulating objectives \\
2. Setting goals \\
3obilizing & 3. Criticize the plan \\
1. Raising awareness in a community about needs \\
Training & 2. establishing or supporting organizational structures within the community \\
& 1. Participation in formal or informal training activities to enhance communication \\
Project Implementation & 2. construction, maintenance and financial management skills \\
& 1. Provide money and labour power \\
Monitoring and Evaluation & 2. Procure goods and services \\
& 1. Data collection and analysis \\
\hline
\end{tabular}

As table 3 shows the roles played by communities in subprojects, the study found that the level of community participation was interactive. This was due to the fact that they took part in joint need assessment, planning, implementation and monitoring together with TASAF management. In affrming this, one of the TASAF officers said that: 
“...TASAF II employed community driven bottom up approach in which community actively particpated in decision making over the sub projects. Through village meetings, community identify their priorities, made decision, planned, implemented and monitored their sub projects...community fetched water, purchased material and kept recording of project."

In a views of the TASAF II officer was noted that community had a greater chance in participating of sub project activities. For effective participatory monitoring and evaluation, community members should actively participate throughout project cycle; namely, pre-sub project cycle, sub project cycle and post sub project cycle. Also, the findings are corresponding to TASAF phase II objective which based on community driven approach to promote community empowerment and capacity building. It was aslo found that TASAF II phase II involved community at interactive level whereby community participated in needs assessment, planning, implementation and monitoring and evaluation.

\subsection{Methods Used in Community Participation on Monitoring and Evaluation}

Methods used to engage community participation in monitoring and evaluation in sub-projects might sometimes hinder or facilitate effective community decision making in their sub-projects. The findings indicate that about 35 (64 percent) out of 55 respondents they were interviewed as part of the community group through village meeting. The village meeting used as platforms of making decision at grass root level in Tanzania and its part of the administrative structure in the local government authorities. Four respondents (7 percent) participated in monitoring and evaluation through direct observations of sub-projects sites and 16 (29 percent) through focus group discussion. The group who involves in group interview argued that they made decisions of their sub project through village meetings. They continued to argue that different views were raised and discussed by the community members. This can be asserted by one of the respondents who had to say this:

“...through village meeting, community members identify different needs, discussed and then come up to an agreement with one identified priority which had to be agreed by all community members. TASAF officers had a role to facilitate our discussion."

The respondents who indicated that they used focus group discussion to make decision on their sub projects argued that they had discussion among themselves and sometimes with village fund officer. And those been part of the direct observation argued that several times village fund officer with his team visited together with sub project beneficiaries to their project area, observe and decide what corrective action should be taken. This also was attested by one of the TASAF officers who said that:

“...after desk appraisal of sub project proposal, field appraisal is carried out between community members and District Council officers in the sub-projects area. Also, during sub-projects implementation, we and sub projects beneficiaries visited sub projects area and made corrective measures pertaining the sub projects."

The findings also revealed that TASAF II employed participatory rural appraisal techniques in M\&E. However, community group interview was mostly used throughout the sub-projects cycle. This is because to the fact that, the technique include all community members in time when it come to the issue of making decision. Community driven development it enhance community participation at grass roots level and increases the success and sustainability of projects.

\subsection{Identified Challenges of Community Participation in Monitoring and Evaluation}

The study wanted to find out if there were any challenges of involving community in $\mathrm{M} \& \mathrm{E}$ of TASAF II project. Almost all (52) 95 percent out of 55 of the respondents indicated that there were challenges in participating in M\&E, while (3) 5 percent indicated that they did not know if there is challenge or not. However, those respondents who indicated that for them to participate on monitoring and evaluation faced with challenges. The challenges identifies by this group summarized in Figure 1.

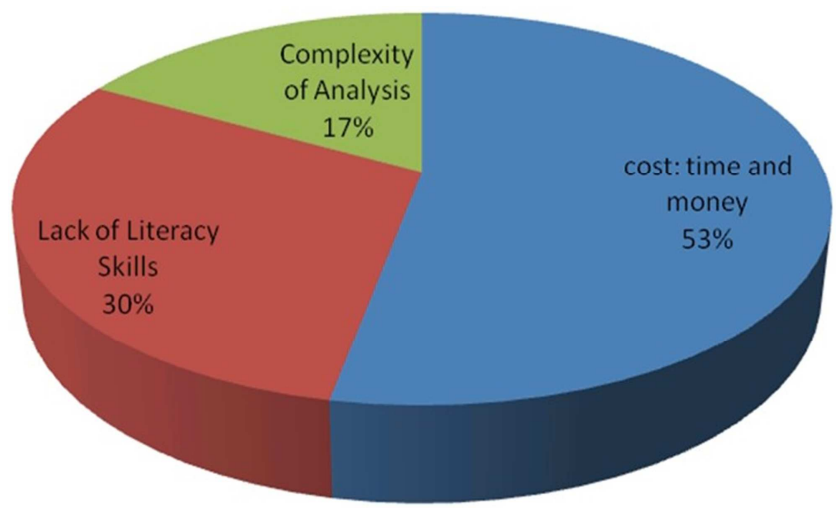

Figure 1. Respondents' Views on Challenges of Monitoring and Evaluation $(N=55)$.

\subsubsection{Cost: Time and Money}

Figure 1: indicates that 53 percent out of 55 of the beneficiaries argues that time and money is a big challenge to them in monitoring and evaluation of the TASAF II subprojects. Participation in M\&E takes much time because it needs people to participate in all stages; planning, implementation and monitoring and evaluation. The findings indicate that most of the beneficiaries live in scatted rural areas which sometimes they need to travel up to the district headquarters. Most of the project sites and home of beneficiaries are almost more than 50 kilometers to the Districts office. Therefore, they use much time in the road and in government officer at district levels as well as money for transport in that government office. The findings showed also that some of the sub-projects established far from the other beneficiaries, for that reason, the beneficiary they are daily or a day in week commuting to the project site. It was also found out that TASAF projects needed community to 
volunteer much of their time to provide labour power and at the same time they are needed to engage in their daily activities. One of the respondents said that:

"...it is volunteer job and project is not completed on time...sometime I lack even bus fare to visit the project. Therefore, TASAF should find means to facilitate us economically. Most of TASAF sub projects were not completed on time; this discourages the community to volunteer for a long period of time."

In line with this respondent's argument, the government officer also noted that it also cost in the part of the government. This is because the officer who visited subprojects site needed transport and subsistence allowance (per diem). In Tanzania transport and subsistence allowance for one government officer per day it ranges from Tanzania shillings 60,000-100,000 per day, according to government standing order [29].

\subsubsection{Lack of Skills}

Moreover, Figure 1 indicates that about 30 percent of the respondents argued that lack of literacy skills in M\&E is among the challenges in TASAF II. In addition to that, respondents reported that community skills in learning are very low therefore, much time and resources were needed to ensure effective participation in M\&E. One of the TASAF officers had to say the following:

"...involving community in all stages of the sub projects is very challenging in the sense the process goes very slow. Some communities needed first to know about and even during project initiation. Since many communities have low literacy skills, it took much to come into agreement what should to be implemented. Some community members did not know how to read and write, that is why even preparing sub projects report is a problem."

This indicates that community participation in development needs commitment, capacity and resources so as to ensure community is empowered and capacity is built to them.

\subsubsection{Complexity of Analysis}

Lastly, it indicated that 16 percent of all respondents argued that complexity of data analysis of collected information is a challenge. The respondents lamented that they had no enough knowledge and skills in analyzing the information they had collected. They added that trainings which were provided by TASAF not adequately help them in analyzing the collected information.

\subsection{Opportunities}

We intended to examine whether community participation in M\&E had created an opportunities to the project beneficiaries, TASAF II project and development project in general. The findings indicated that 15 ( 27 percent) out of 55 respondents said that it ensures sustainability of the sub projects, 25 (46 percent) argued that involving community in M\&E promotes transparency and accountability, 8 (15 percent) said it promoted a sense of ownership of the subprojects and 7 (12 percent) indicated proper allocation of resources resulted from involving community in M\&E. The results are summarized in Table 4.

Table 4. Opportunities of Involving Community in Monitoring and Evaluation.

\begin{tabular}{lll}
\hline Benefits of community participation on monitoring and evaluation on TASAF II sub-projects & Frequency & 15 \\
\hline Sustainability of the sub-projects & 27 \\
Transparency and accountability & 46 & 8 \\
Promote sense of ownership & 15 & 7 \\
Proper allocation of resources & 12 & 55 \\
Total & 100 \\
\hline
\end{tabular}

\subsubsection{Sustainability of the Sub-Projects}

The findings indicate that community participation in monitoring and evaluation enhances sustainability of projects since the community gets knowledge and skills on the sub projects. This knowledge can easy for them to operate and maintain sub projects. In relying to this during group discussion, one of the village government officials had to say on this:

"When community is involved in monitoring and evaluation of any project, usually there is a possibility of the longer life of the projects since community get knowledge and skills of operating and maintaining the project. In this village we have good examples of projects which stopped after their implementation because we were not actively involved... but for TASAF apart from some challenges, still we maintain our dispensary for five years now"

The argument of the government officer indicates affirms that, community participation in $M \& E$ on any project will improve the match between what a community needs and what it obtains. This ensures sustainability and consistency with the preference of the target group. Current emphasis on communities participating in monitoring and evaluation of any project enhances the longer life of the project and on the same time community is part and parcel of the developed projects.

\subsubsection{Transparency and Accountability}

Transparency and accountability are among of the benefits of involving community in M\&E of development projects. This indicates that the respondents in this category believed that governance issues are responsible for M\&E process of TASAF II sub-projects in Bagamoyo District. It can be noted that community participation in $\mathrm{M} \& \mathrm{E}$ is important to make sure that beneficiaries address the real needs of communities in the most appropriate way of any developed project such as TASAF II projects. This also was affirmed by one of the TASAF officers who contend that: 
"TASAF project is a good example of the projects in which its beneficiaries know amount of project fund and its expenditure. Transparency in the implementation promotes all project stakeholders to be more accountable to the project resource. It is very easy to identify any misuse of the project resource since local community act as watch dog to other implementers."

The comment from the government officer indicates that community participation in M\&E increases efficiency and effectiveness in the implementation and management of development project. Involving community in $\mathrm{M} \& \mathrm{E}$ is a functional to transparency and accountability of the resources entrusted towards the community beneficiaries, donors and local institutions.

\subsubsection{Promote Sense of Ownership}

The findings indicated that community participation in M\&E developed a sense of ownership because even the voice of the voiceless been adhered been integrated in the decision making process. In the FGDs one of the respondents in justifying this said:

"... if there is a real participatory approach in monitoring and evaluation, TASAF II is a good example. We are empowered through training and active involvement in the project. This makes community to own and control the project which promotes them to make decisions for corrective action..."

Participating in monitoring and evaluation from the beginning to the end of the project can give stakeholders a sense of ownership over the results. Recognizing beneficiaries in M\&E process builds confidence and pride in the community, and among participants. Furthermore, the study revealed that community involvement in M\&E promotes local people learning. One of the TASAF officers had to comment on this:

“...involving community in M\&E helps to build confidence to community, created sense of ownership and empowered community. Also, it helps to build an informed and responsible citizenry with a sense of ownership, allowing the implementers to get buy-in and develop partnerships with stakeholders"

This indicates that community involvement in $\mathrm{M} \& \mathrm{E}$ attempt to mobilize communities for action with the hope of instilling a sense of ownership and commitment to the development activity. Recognizing beneficiaries in M\&E process builds confidence and pride in the community, and among participants.

\subsubsection{Proper Allocation of Resources}

Involving community in $\mathrm{M} \& \mathrm{E}$ ensured proper allocation of resource for the reason that community would identify clearly their proper needs which ensured appropriate allocation of fund. The findings indicate that some of the beneficiary they change their initial projects targets through participation in M\&E. In the study, it was found that the Dunda poultry keeping sub-projects beneficiaries change idea of their sub project. Formally, they agreed to keep Malawi chicken species which takes six months to sell but later they changed and keep broiler species which takes four to six weeks to mature. This change was a bottom-up approach rather than top-up approach, and done by the beneficiaries themselves without the influence of the TASAF II officers. The findings also indicate that involving community in M\&E systems help project staff and community to analyze what is working well, what is not working and why is not working. It was also found that community members reflect and assess the progress of the project towards achieving its goals and adjust activities as required.

\section{Discussion}

This paper aimed at documenting the challenges and opportunities of community participation in monitoring and evaluation of the government sub-projects in Bagamoyo District, Tanzania. The finding from this study indicated that community participation is important in monitoring and evaluation given that they contribute to the sustainability of the sub-projects. It is also; ensure the good governance of in the management and development of the established subprojects. Despite the contribution of community through participation in monitoring and evaluation, but, still, community participation goes with challenges $[30,31]$. Such challenges of participatory monitoring and evaluation have been well addressed by other scholars [9, 32, 33, 34]. Butterfoss and Mutua assert that community participation can be constrained by lack of literacy skills, insufficient time, and the intensity of analytical work to be undertaken during the evaluation, and the fact that many of the issues covered during the evaluation are not directly relevant to community members [33, 34]. Participation of communities in monitoring and evaluation require many resources such as time, transport and performance related allowance [9, 33]. Collection and documentation of wide range of information requires skills that are lacking in the communities [9, 35]. Therefore, it necessitates much time and resource for capacity building.

Estrella et al., argues that PM\&E as a process of learning, it becomes more complex, since more stakeholders including the community within the entire program/project become involved in M\&E which have varies interest and needs [9]. This makes the process of analyzing the collected information to be more complex because choosing a method which would complement the interest of all stakeholders is very difficult [36]. Evaluators also, are challenged by putting a participatory evaluation into practice, especially with a number of different stakeholders who often have different needs and interest. Harris et al notes that it is a challenge to identify which tools are most appropriate for understanding the impact of different interventions [37]. The PM\&E needs great thought in the choice of particular methods of collecting information. World Bank contends that PM\&E approach is more complex than generally assumed and if participatory values and systems are not present in an organization, introducing PM\&E needs discussion on how the approach can be adopted more widely [38]. 
IFC notes that community participation in development projects "strives to be a learning process which enables people to reflect on past experience, examine present realities, revisit objectives, and define future strategies, by recognizing different needs of stakeholders and negotiating their diverse claims and interests" [39:13]. This been like a culture process because it helps community and evaluators to understand different issues, and it is a political process. Community and other stakeholders would share experiences and understanding the needs of each other, this creates a good environment for clear decisions making and empowering communities [40].

The rationale behind participation of communities in planning monitoring and evaluation system is to allow them effectively develop indicators for measuring progress and identify objectives to be attained [41]. This is usually done during the planning stage. Therefore such an approach combines methods and tools that communities can use to participate in development based on the explicit recognition, identification and clarification of their own local values. Bartecchi pointed out that participatory $M \& E$ is an integral part of community empowerment that allows communities themselves to set their own goals, strategies and indicators and to actively monitor and evaluate whether they are moving towards achieving them [42]. In addition, they contend that community involvement in M\&E enhances transparency and accountability in resource use [43]. Costa asserted that local people should be involved in monitoring and evaluation by focusing on activities that are really they act upon [44]. It is pointed out that implementing agency should be ready to discuss findings that local people act on. Community participation in M\&E should actively involve grassroots in planning, implementation and monitoring and evaluation. The report of Cooksey and Kikula found that community applied data to adjust project activities, reflect and make decisions on various aspects of community initiatives [45]. In addition, information used to ensure accountability to their priorities, through effective communication and feedback mechanisms.

Community participation in M\&E systems enhances local learning, management capacity and skills in assessing the quality of service delivery [46]. Besides tracking and monitoring government decision-making, the system involves communities in research and builds their capacity to bring about significant change and facilitates in-depth learning by large numbers of people on pertinent issues. However, community participation is not to everyone in an identifiable community, since indigenous elites already have a strong voice in decision making, but rather to the poor majority with little access to resources and power [47].

\section{Conclusion}

Despite the benefits realized in community participation in $M \& E$ of TASAF project phase II, M\&E was inadequately implemented. The communities had inadequate knowledge on M\&E, inadequate sharing of information between TASAF and communities, and among sub project beneficiaries themselves. Moreover, communities did not participate in designing TASAF project phase II and inappropriate trainings were provided to communities. Time was a major challenge for communities to participate fully in M\&E. In order to ensure effective community participation in M\&E in TASAF project, the government should review TASAF II monitoring and evaluation system to ensure local communities are more active in decision making. Two, the government should also allocate more financial, human resources and time in M\&E system to enhance community participation in TASAF projects. Three, the government should formulate monitoring and evaluation policy in each sector and not to incorporate monitoring and evaluation as an aspect in the policies and programmes. Four, the government through TASAF should empower local government authorities (LGAs) especially village council members so as to provide adequate support to effectively guide communities to implement and manage their project. Five, the government should build capacity to village councils' members to ensure effective participation of the communities, proper keeping of sub project records and timely preparation of the reports. Six, the government should also provide the local people with technical support for much longer time so that they can gain enough knowledge and skills to ensure proper management of their projects. Seven, the government should continue to provide training to its staff members on PM\&E and community members so as to raise their level of awareness on the process.

\section{Recommendations for Further Study}

According to TASAF II, community management committee of a particular sub project is responsible for collecting data on implementation of sub projects on behalf of the village council. The ward development committee would collect data from the village councils for submission to the districts. Therefore, another study can assess participation at the local government in the implementation of projects. Community institutions such as CBOs and CSOs have frequently been mentioned in TASAF framework and other participatory monitoring and evaluation literature as important institutions in monitoring and evaluation. Other study can focus on the role of CSOs in monitoring and evaluation of TASAF project.

\section{References}

[1] Lewis, D. The Management of Non-Government Development Organisations, Routledge 270 Madison, AVE New York, NY 10016. 2007.

[2] Wasilwa, C. Effect of Community Participation on Sustainability of Community Based Development Projects in Kenya. 2015.

[3] Morgani, L. Community participation in health: perpetual allure, persistent challenge, Health Policy and Planning; 16 (3): 221-230. 2001. 
[4] Thomas, P. Challenges for participatory development in contemporary development practice, Development Bulletin No.75. Resources, Environment and Development, Journal of the Development Studies, Australia National University. 2013.

[5] Kwamie, $\mathrm{K}$ and Nabyonga-Orem, J. Improved harmonization from policy dialogue? Realist perspectives from Guinea and Chad, BMC Health Services Research, 16 (Suppl 4):222 DOI 10.1186/s12913-016-1458. 2016.

[6] Rajalahti, R, Woelcke, J and Pehu, E. Monitoring and Evaluation for World Bank Agriculture and Rural Development Discussion Paper 20. 2005.

[7] Kilewo, E. G and Frumence, G. Factors that hinder community participation in developing and implementing comprehensive council health plans in Manyoni District. Tanzania, Global Health Action, 8: 26461 http://dx.doi.org/10.3402/gha.v8.26461. 2015.

[8] UNDP. Handbook on Planning, Monitoring and Evaluating for Development Results, New York USA. 2009.

[9] Estrella, M. with J. Blauert, D. Campilan, J. Gaventa, J. Gonsalves, I. Guijt, D. Johnson \& R. Ricafort. Learning From Change: Issues and Experiences in Participatory Monitoring and Evaluation, Intermediate Technology Pub., London. 2000.

[10] Dube, N. Evaluating Community Participation in Development Projects: Thesis presented in partial fulfillment of the requirements for the degree of Master of Philosophy (Social Science Methods) at the University of Stellenbosch. 2009.

[11] Nour, M. A. Challenges and Advantages of Community Participation as an Approach for Sustainable Urban Development in Egypt, Journal of Sustainable Development Vol. 4, No. 1. 2011.

[12] United Republic Tanzania. Millennium Challenge AccountTanzania: Monitoring and Evaluation Plan, Ministry of Finance. Dar es Salaam, Tanzania. 2012.

[13] World Bank (2007) The Tanzania Second Social Action Fund (TASAF II). Knowledge Sharing and Learning for Better Delivery of Results. Social Development, 41921. World Bank Group.

[14] O’Mara-Eves, A., Brunton, G., McDaid, D., Oliver, S., Kavanagh, J., Jamal, J., Matosevic, T., Harden, A and Thomas, J. Community engagement to reduce inequalities in health: a systematic review, meta-analysis and economic analysis, Public Health Research, Volume 1, Issue 4, ISSN 2050-438. 2013.

[15] Cobbinah, J. E. Power Relations in Community Participation: Does it really matter? Journal of Economics and Sustainable Development, Vol.6, No.13. 2015.

[16] Raniga, T. and Simpson, B. Community Participation: Rhetoric or reality? Social work: A Professional Journal for the Social Worker, 38 (2). 2002.

[17] Asia Development Bank. Strengthening Participation for Development Results; An Asian Development Bank Guide to Participation, Asia Development Bank, Philippines. 2012.

[18] Howard-Grabman, L., Miltenburg, A. S., Marston, C and Portela, A. Factors affecting effective community participation in maternal and newborn health programme planning, implementation and quality of care interventions, BMC
Pregnancy and Childbirth, 17:268 DOI 10.1186/s12884-0171443-0. 2017.

[19] Zittel, T. and Fuchs, D. (eds), Participatory Democracy and Political Participation. Can participatory engineering bring back? Routledge, USA. 2007.

[20] Sanoff, H. Community Participation Methods in Design and Planning, John Wiley \& Sons, New York USA. 2000.

[21] Chambers, R. Whose Reality Counts? Intermediate Technology Publications, London. 1997.

[22] Mwanzia, J and Strathdee, R. Voices in development management: Participatory Development in Kenya. Ashgate Publishing Limited, England. 2010.

[23] Anatole, S. Public Involvement through Participatory Monitoring and Evaluation: Research Report, IP Stream, CURA August 30. 2005.

[24] Mansuri, G. and Rao, V. Community Based and Driven Development: a Critical Review, World Bank Policy Research working paper 3209, Washington DC, USA. 2004.

[25] Nekwaya, J. Assessing community participation in development planning and service delivery: A case study of the Omusati Regional Council Thesis presented in partial fulfillment of the requirements for the degree of Master of Sustainable Development Planning and Management at the University of Stellenbosch. 2007.

[26] Gautum, A. Profile of Current Coastal Tourism in Bagamoyo District, Tanzania and Opportunities for Development of Ecotourism. TCMP Technical Report, USAID. 2009.

[27] Patton, M. Qualitative evaluation and research methods (pp. 169-186), Beverly Hills, CA: Sage. 1990.

[28] Berg, B. L. Qualitative Research Methods for the Social Sciences. Allyn and Bacon, University of Michigan. 2001.

[29] Tanzania. Standing Order for the Public Services $3^{\text {rd }}$ Edition, Dar es Salaam, Tanzania.

[30] Gaventa, J and Barrett, G. Mapping the Outcomes of Citizen Engagement, World Development, Vol. 40, No. 12, pp. 2399 2410. 2012.

[31] Robertson, L., Mushati, P., Skovdal, M., Eaton, W. J., Makoni, C. J., Crea, T., Mavise, G., Dumba, L., Schumacher, C., Sherr, L., Nyamukapa, C and Gregson, S. Involving Communities in the Targeting of Cash Transfer Programs for Vulnerable Children: Opportunities and Challenges, World Development Vol. 54, pp. 325-337. 2014.

[32] Mebrahtu, E. Putting Policy into Practice: Participatory Monitoring and Evaluation in Ethiopia. 2004.

[33] Butterfoss, F. D. Process Evaluation for Community Participation, Annu. Rev. Public Health, 27:323-40 doi: 10.1146/annurev.publhealth.27.021405.102207. 2006.

[34] Mutua, M. F. Influence of Beneficiary Participation on Effective Monitoring and Evaluation of Community Based Water Projects in Kenya: The Case of Kiabaibate-Nchura in Tigania West Sub-County, Unpublished Master's Thesis, University of Nairobi. 2015.

[35] Stringer, L. C., A. J. Dougill, E. Fraser, K. Hubacek, C. Prell, and M. S. Reed. Unpacking "participation" in the adaptive management of social-ecological systems: a critical review. Ecology and Society 11 (2): 39. 2006. 
[36] Adams, J and Garbutt, A. Participatory Monitoring and Evaluation in Practice Lessons learnt from Central Asia. 2008.

[37] Harris, J., Croot, L., Thompson, J and Springett, J. How stakeholder participation can contribute to systematic reviews of complex interventions, Epidemiol Community Health, 0:18. doi:10.1136/jech-2015-20570, 2015.

[38] World Bank. Monitoring and Evaluation; Some tools, Methods and Approaches, Washington D. C, USA. 2004.

[39] International Financial Corporation (IFC). International Lessons of Experience and Best Practice in Participatory Monitoring in Extractive Industry Projects; Guidance Note on Designing Participatory Monitoring Program, Common Ground Consultancy. 2010.

[40] Estrella, M. (Ed). Learning from Change: Issues and experiences in participatory monitoring and evaluation, Intermediate Technology Publications. 2003.

[41] Reynolds, H. W and Sutherland, E. G. A systematic approach to the planning, implementation, monitoring, and evaluation of integrated health services, BMC Health Services Research, 13:16. 2013.

[42] Bartecchi, D. The Role of Participatory Monitoring and Evaluation in Community-Based Development; Village Earth Participatory Strategic Planning Workshop-Armenia. 2016.
[43] Cars, M. Studies in International and Comparative Education: Project Evaluation in Development Cooperation: A MetaEvaluative Case Study in Tanzania, Universitets service USAB. Stockholm, Sweden. 2006.

[44] Costa, P. Study on Communicating Evaluation Results, Prepared for the OECD Informal Network of DAC Development Communicators (Dev Com Network) Final Version. 2012.

[45] Cooksey and Kikula, I. When Bottom-Up Meets Top- Down: The Limits of Local Participation in Local Government Planning in Tanzania, Mkuki na Nyota Publisher, Dar es Salaam. 2005.

[46] Kaaria, S. K. and Njuki, J. M. Developing and supporting community-driven participatory monitoring and evaluation of marketing activities: CIAT, Kampala. 2005.

[47] Lukasiewicz, A and Baldwin, C. Voice, power, and history: ensuring social justice for all stakeholders in water decisionmaking, Local Environment, 22:9, 1042-1060, DOI: 10.1080/13549839.2014.942261. 2017. 